\title{
PEMANFAATAN REFLEKTOR TERKONTROL UNTUK PROSES PEMERCEPAT PENGERINGAN KAYU MEBELER
}

\author{
Oleh: \\ Rickyanto $^{1}$, Imam Tazi ${ }^{2}$
}

\begin{abstract}
ABSTRAK: Proses pengeringan kayu mebeler dengan menjemur di bawah sinar matahari memerlukanwaktupengeringan yang lama untuk mencapai massa kering maksimum. Selain itu cacat kayu yang diakibatkan oleh cuaca di lingkungan tidak bisa dihindarkan.Oleh karena itu diperlukan sebuah alat yang mampu memberi solusi masalah tersebut.

pada skripsi inidirancang alat pengering kayu mebeler yang portabel dan mobile menggunakan tenaga matahari dengan kolektor surya plat hitam dan memanfaatkan dua cermin reflektor untuk mengoptimalkan panas dalam oven. Alat yang dirancang berbentuk balok berkaki dengan ukuran luas balok $2 \mathrm{~m} \times 1 \mathrm{~m} \times 0.6 \mathrm{~m}$, dengan panjang kaki berukuran $0.6 \mathrm{~m}$.

Pengering menggunakan reflektor terkontrol dicoba untuk mengeringkan 5 sampel bahan uji (kayu) dengan massa yang berbeda. Begitu pula pada oven non reflektor dan juga pengeringan menggunakan sinar matahari langsung.Target pengeringan dengan alat ini adalah memperoleh hasil penguapan kadar air yang maksimum dan waktu kering maksimum yang minimum.Dari serangkaian percobaan diperoleh hasil pengeringan yang menunjukkan bahwa alat ini lebih optimal. Waktu yang dibutuhkan untuk kering kayu maksimal lebih cepat, begitu pula prosentasi penguapan air menunjukkan nilai yang paling tinggi dibandingkan dengan pengeringan yang lain.
\end{abstract}

Kata kunci: Pengeringan, Energi Matahari, Oven, Reflektor, kadar air

\section{PENDAHULUAN}

Industri besar dan kecil di tanah air kebanyakan masih menggunakan energi minyak bumi. Hal ini disebabkan karena efektivitas dan efisiensinya dapat diandalkan. Padahal cadangan minyak bumi semakin menipis disamping kebutuhan akan minyak bumi semakin besar. kegitan tersebut akan sangat berdampak pada krisis energi secara global. Maka perlu dicari dan dikembangkan pemanfaatan energi alternatif yang merupakan salah satu solusi untuk menanggulangi krisis energi minyak bumi tersebut.

Indonesia yang merupakan daerah sekitar katulistiwa dan daerah tropis dengan luas daratan hampir 2 juta $\mathrm{km} 2$, dikaruniai penyinaran matahari lebih dari 6 jam sehari atau sekitas 2.400 jam dalam setahun. Energi surya dimuka bumi Indonesia mempunyai intensitas antara 0,6-0,7kW/m2.Dari kondisi inilah sangat wajar jika matahari dijadikan sebagai sumber energi alternatif yang mempunyai potensi besar untuk menjawab masalah tersebut.

Salah satu pemanfaatan energi surya yang sangat banyak digunakan adalah pemanfaatannya sebagai pengering makanan. Masing-masing pengering mempunyai karakteristik sendiri-sendiri sesuai dengan kegunaannya. Pengering ikan mempunyai

1,2 Jurusan Fisika Fakultas Sains dan Teknologi UIN Maliki Malang 
karakteristik suhu dan desain yang berbeda begitu pula pada pengeringan tembakau, dan bahan-bahan makanan lainnya.Dalam pengeringan kayu dibutuhkan perlakuan yang khusus pula, pengeringan kayumembutuhkan proses yang lebih lama dan membutuhkan suhu yang tinggi. Proses pengeringan kayu tidak banyak membutuhkan aturan-aturan yang rumit seperti pada proses pengeringan ikan, tembakau, dan bahan-bahan makanan lainnya.Tujuan dari proses pengeringan kayu hanyalah bagaimana supaya kadar air pada kayu bisaberkurang dengan dengan cepat, sehingga kayu yang sudah kering mempunyai kadar air yang kecil agar bisa disimpan dalam waktu yang lama dan tidak mengalami perubahan bentuk akibat pemuaian karena perubahan suhu.

Pengeringan kayu dapat dilakukan dengan dua cara, yaitu pengeringan alami dan pengeringan buatan. Pada pengeringan alami (kering udara)panas yang digunakan adalah sinar matahari. Kerugian dari cara ini adalah: memerlukan waktu yang relatif lama. memerlukan areal yang cukup luas, cacat yang timbul sulit untuk diperbaiki.

Pengeringan buatan,merupakan pengeringan dengan menggunakan alat untuk mengeringkan kayu dengan sumber panas dari pemanasan buatan seperti : bersumber dari elemen listrik, energi fosil, atau bahkan limbah kayu. Biasanya berupa Oven (Soeyanto, 1974). Kerugian dari cara ini: biaya atau modal yang besar,menggunakan peralatan yangmahal, pelaksanaanya tidak mudah sehingga memerlukan tenaga ahli, bahan bakar yang digunakan adalah energi fosil, atau listrik, atau bahan bakar limbah kayu yang mempunyai nilai dari segi ekonomi dan lingkungan.

Dari dua jenis pengeringan kayu tersebutkami berinisiatif untuk merancang dan membuat alat pengering kayu yang memanfaatkan energy matahari sebagai sumber panasnya.Dengan tujuan menghasilkan sebuah alat pengering yang lebih efektif, efisien, dan bernilai ekonomis dibandingkan dengan yang sudah ada.Diharapkan nantinya dapat membantu masyarakat, utamanya masyarakat industri perkayuan (mebel) untuk bisa meningkatkan kwalitas hasil industri mereka.

\section{KAJIAN TEORI}

Matahari merupakan sumber energi untuk kehidupan yang berkelanjutan. Panas matahari menghangatkan bumi dan membentuk iklim, sedangkan cahayanya membuat siang hari terang dan dipakai oleh tumbuhan untuk fotosintesis. Tanpa matahari, tidak akan ada kehidupan di bumi karena banyak reaksi kimia yang tidak dapat berlangsung (Lang, 2006).

Diameter matahari sekitar 14 x $105 \mathrm{Km}$ atau 109 kali diameter bumi. Massa matahari333.400 kali massa bumi atau secara pendekatan 1,99 x $1030 \mathrm{Kg}$. Dengan mengetahui ukurandan massa matahari maka diperoleh densitas matahari rata-rata 1,41 $\mathrm{g} / \mathrm{cm} 3$ yang lebih rendahseperempat kali dibandingkan densitas bumi rata-rata(Bayon Jasyono, 2006). 
Radiasi adalah proses perpindahan panas melalui gelombang elektromagnetik ataupaket-paket energi (photon) yang dapat dibawa sampai pada jarak yang sangat jauh tanpamemerlukan interaksi dengan medium (ini yang menyebabkan mengapa perpindahan panasradiasi sangat penting pada ruang vakum), disamping itu jumlah energi yang dipancarkansebanding dengan temperatur benda tersebut. Kedua hal tersebut yang membedakan antaraperistiwa perpindahan panas konduksi dan konveksi dengan perpindahan panas radiasi (Koestoer, 2002).

Setiap menit matahari meradiasikan energi sebesar 56 x $10^{26}$ kalori. Energi mataharipersatuan luas pada jarak jauh dari permukaan bola dengan matahari sebagai pusat bulatandan jari-jari bulatan 150 juta $\mathrm{Km}$ (Tjasyono, 2006):

$$
S=\frac{56 \times 10^{26} \mathrm{kalmenit}^{-1}}{4 \pi x\left(15 \times 10^{12} \mathrm{~cm}\right)^{2}}
$$

2,0 kal.cm ${ }^{-2}$ menit $^{-1}$ (pembulatan) $=$ Langley menit ${ }^{-1}$

$S=2,0$ Ly menit $^{-1}$, yang disebut konstana matahari

Dengan demikian energi radiasi matahari yang diterima bumi yang berjari-jari 6370 $\mathrm{km}$ dapat dihitung seperti berikut :

$$
\begin{aligned}
\mathrm{E}_{\mathrm{b}} & =\pi \mathrm{r}^{2} \mathrm{~S} \\
& =3,14 \times\left(637 \times 10^{6} \mathrm{~cm}\right)^{2} 2 \mathrm{kal} \cdot \mathrm{cm}^{-2} \cdot \mathrm{menit}^{-1} \\
& =355 \times 10^{18} \mathrm{kal} \cdot \mathrm{menit}^{-1} \\
& =3,67 \times 1021 \mathrm{kal} \cdot \mathrm{hari}^{-1}(\text { Tjasyono, 2003). }
\end{aligned}
$$

Energi sebesar ini cukup untuk menciptakan 100 juta badai guruh (petir) atau 100 milyar tornado.

Permukaan dari benda hitam adalah permukaan yang paling ideal untuk menyerap kalor, yang mempunyaisifat-sifat:

1) Benda hitam menyerap semua radiasi yang disengaja (irradiasi) tanpa melihatpanjang gelombang dan arah datangnya sinar (diffuse).

2) Pada semua temperatur dan panjang gelombang yang diizinkan, tidak ada permukaanyang dapat menghasilkan energi lebih banyak daripada benda hitam.

3) Walaupun emisi radiasi yang dihasilkan oleh benda hitam adalah fungsi dari panjanggelombang dan temperatur, dan tidak bergantung pada arah datangnya sinar (Koestoer, 2002).

Pada umumnya, bahan yang dapat menghantar arus listrik dengan sempurna (logam) merupakan penghantar yang baik juga untuk kalor dan sebaliknya. Selanjutnya bila diandaikan sebatang besi atau sembarang jenis logam dan salah satu ujungnya diulurkan ke dalam nyala api. Dapat diperhatikan bagaimana kalor dipindahkan dari ujung yang panas ke ujung yang dingin. Apabila ujung batang logam tadi menerima energi kalor dari api, energi ini akan memindahkan sebahagian energi kepada molekul dan elektron yang membangun bahan tersebut. Molekul dan elektron merupakan alat pengangkut kalor di dalam bahan menurut proses perpindahan kalor konduksi. Dengan demikian dalam proses pengangkutan kalor di dalam bahan, aliran electron akan memainkan peranan penting 
Dalam kasus plat kolektor surya, perangkap terbaik radiasi matahari adalah permukaan hitam. Pada permukaan ini radiasi matahari diserap dan dikonversi dari energi cahaya menjadi energi panas(Tjasyono, 2003).

Sifat dari permukaan radiasi (emisivitas) didefinisikan sebagai perbandingan radiasiyang dihasilkan oleh permukaan benda hitam pada temperatur yang sama. Emisivitasmempunyai nilai yang berbeda tergantung kepada panjang gelombang dan arahnya. Nilaiemisivitas bervariasi dari $0-1$, di mana benda hitam mempunyai nilai emisivitas 1 (Koestoer, 2002).

Kaca hanya dapat melewatkan cahaya dengan panjang gelombang tertentu yang kecil sehingga ketika panjang gelombang cahaya membesar maka cahaya tidak akan dapat keluar dari rumah kaca lagi karena panjang gelombangnya membesar dan energinya akan membuat suhu dalam rumah kaca menjadi sangat panas karena terakumulasi terus menerus (Aris, 1995).

Cahaya merupakan sebuah gelombang elektromagnetik. Biladipanaskan atau diserap, cahaya memperlihatkan juga sifat-sifat partikel. Cahayadipancarkan oleh muatan listrik yang dipercepat yang telah diberi kelebihanenergi oleh kalor atau oleh pengosongan muatan listrik. Laju cahaya merupakankonstanta fisika fundamental. Pada gambar 2.1 diperlihatkan suatu berkasgelombang yang arahnya membuat sudut Oiterhadap normal bidang batas.Misalkan medium mempunyai 1 kecepatan gelombang sebesar V1 dan medium 2mempunyai kecepatan gelombang sebesar V2 yang lebih kecil dari V1 (Sears danZemansky, 2003).

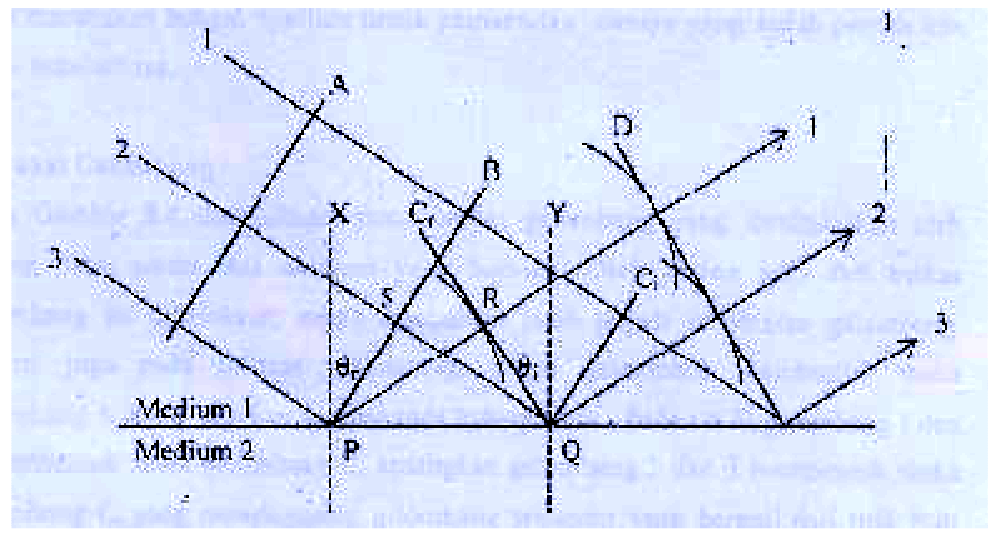

Gambar 1 Refleksi gelombang dengan prinsip Huygens

Sebelum mencapai bidang batas gelombang 1, 2 dan 3 mempunyai mukamukagelombang yang sejajar, yaitu muka gelombang A dan B. Misalkan kitaambil $\mathrm{t}=0$ pada saat semua gelombang mempunyai muka gelombang $\mathrm{B}$. Padasaat $\mathrm{T}=\mathrm{T}$, gelombang 1 dan 2 membentuk gelombang $C_{1}$ yang masih sejajardengan muka gelombang $B$. Oleh karena gelombang 3 di titik $\mathrm{P}$ sudah menjadigelombang sekunder, maka gelombang 2 dan 3 membentuk muka gelombang $\mathrm{C}_{\mathrm{r}}$ yang menyinggung gelombang bola sekunder di titik $\mathrm{R}$. 
Kayu adalah bahan yang kita dapatkan dari tumbuhan-tumbuhan dalam alam dan termasuk vegetasi hutan. Tumbuhan-tumbuhan yang dimaksud disini adalah pohonpohonan (strees)(Soeyanto, 1974).

Mebel adalah kata benda massa yang mencakup semua barang seperti kursi, meja, dan lemari.Dalam kata lain, mebel adalah semua benda yang ada di rumah dan digunakan oleh penghuninya untuk duduk, berbaring, ataupun memuati benda kecil seperti pakaian atau cangkir. Bahan dasar mebel terbuat dari kayu(Soeyanto, 1974).

Kayu bersifat menyerap uap udara jika kandungan udara cukup banyak, sebaiknya jika udara disekitarnya kering, uap air akan dilepaskan oleh kayu. Hal ini mengakibatkan kandungan air di dalam kayu tergantung kelembaban udara di sekitarnya(Soeyanto, 1974).

Kadar air ditentukan dengan rumus :

dengan

$$
\text { kadar air }=\frac{a-b}{b} \times 100
$$

$\mathrm{a}=$ massa kayu yang masih basah

$\mathrm{b}=$ massa kayu setelah kering(Soeyanto, 1974).

\section{METODE PENELITIAN}

\section{A. Desain Alat}

\section{Perancangan Alat}

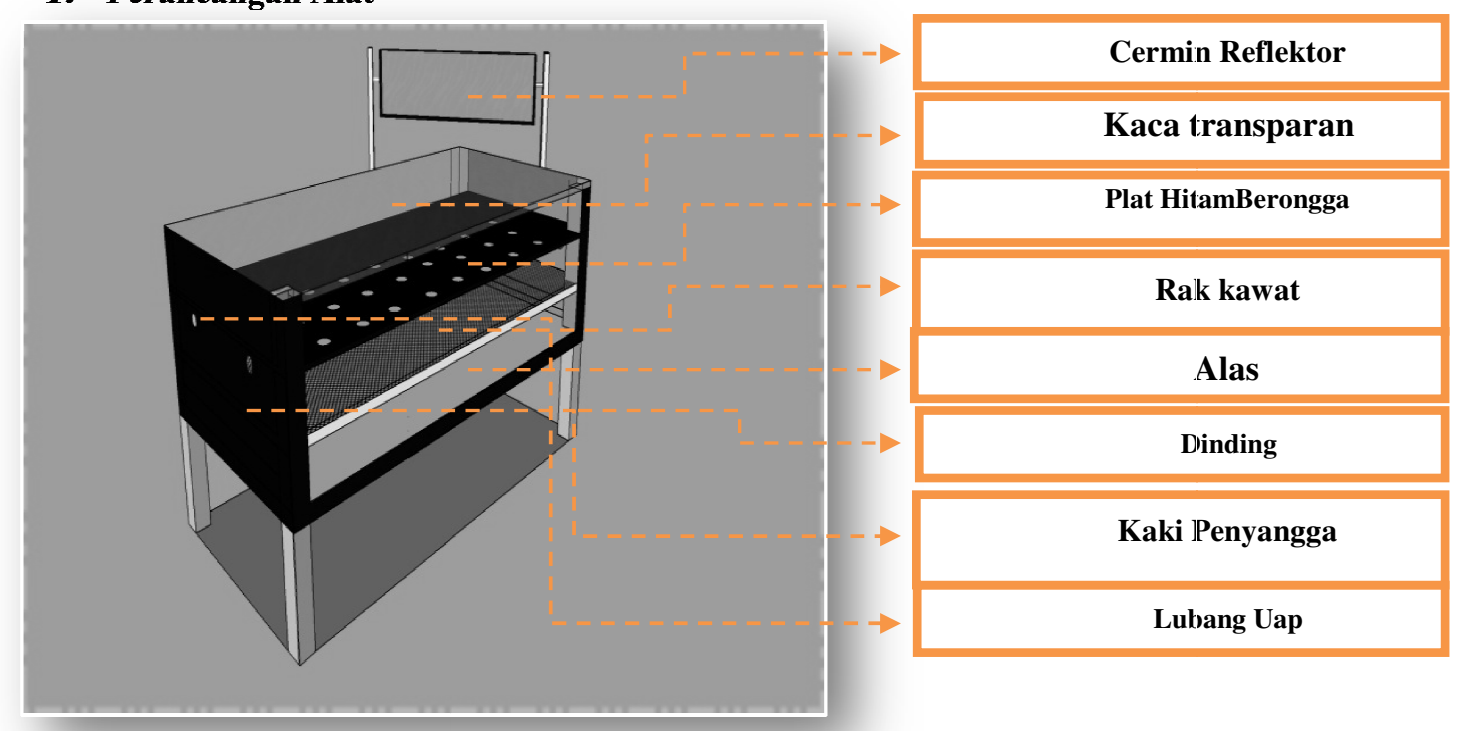

Gambar 1Rancang Bangun Oven Tenaga Matahari Menggunakan Reflektor

Keterangan :

1. Cermin reflektor: merefleksikan sinar matahari sehingga semua permukaan sisi dinding tabung oven dapat tersinari secara sempurna.

2. Kaca transparan: medium untuk mengkonversi radiasi matahari menjadi panas dalam ruangan memanfaatkan asas rumah kaca. 
3. Plat Alumunium hitam berongga: kolektor penangkap atau penyerap kalor dengan lubang sebagai pendistribusi tekanan panas dari ruangan efek kaca transparan untuk dikumpulkan di ruangan bahan.

4. Rak kawat: tempat pengujian bahan

5. Dinding: dinding sekaligus kolektor penangkap atau penyerap panas dengan bahan terbuat dari seng yang diberi warna hitam.

6. Lubang Penguap: penguap

7. Alas: alas terbuat dari seng.

8. Kaki penyangga: untuk menyangga tabung oven.

Berikut kriteria desain alat di atas:

1. Tabung pemanas berukuran panjang 2 meter, tinggi 0,6 meter, lebar 1 meter.

2. Tinggi kaki berukuran 0,6 meter.

3. Plat seng ketebalannya $0,2 \mathrm{~mm}$.

4. Plat alumunium ketebalannya $0.4 \mathrm{~mm}$.

5. Kaca transparan ketebalannya $0,5 \mathrm{~cm}$.

6. Kecuali kaca, semua permukaan diwarnai hitam suram dengan menggunakan cat bermerek emko.

7. Dua cermin reflektor berukuran 1 x 0,6 meter dengan kaki penyangga $60 \mathrm{~cm}$.

\section{Teknik Pengambilan Data}

Variable uji yang digunakan adalah massa kayu dengan tiga pengamatan yang berbeda, pengamatan yang pertama dilakukan dengan melakukan uji eksperimen pengeringan secara langsung di bawah terik matahari dalam selang waktu yang ditentukan, pengamatan yang kedua pengeringan dilakukan di dalam alat pengering tenaga surya yang sudah siap uji, pengamatan yang ketiga pengeringan dilakukan di dalam alat pengering tenaga surya yang sudah siap uji dengan memanfaatkan pantulan cahaya matahari menggunakan cermin (reflektor terkontrol) untuk memperoleh penyinaran matahari secara sempurna pada alat yang siap uji.

Langkah-langkah pengambilan data antara lain:

1. Komponen alat dirakit dan siap uji seperti Gambar 1

2. Menjemur bahan (kayu) dalam alat pengering yang sudah siap uji dengan variabel massa basah kayu yang berbeda.

3. Mulai melakukan pengambilan data dengan mengukur massa sebelum dikeringkan sampai massa yang sudah melalui proses pengeringan dalam selang waktu yang ditentukan.

4. Langkah tersebut diulang dan tiga pengambilan data dengan menggunakan pemanas yang berbeda sebagai perbandingan, maka ketiganya diberi perlakuan sama.

\section{Teknik Analisis Data}

Untuk mengetahui massa kering maksimum dapat diperoleh dengan menentukan banyaknya kadar air dalam kayu yang berhasil dikeluarkan dengan persamaan: 


$$
\text { kadar air }=\frac{a-b}{a} \times 100 \%
$$

dengan:

$\mathrm{a}=$ massa kayu sebelum pengeringan

$\mathrm{b}=$ massa kayu setelah kering

Adapun untuk mengetahui keefektifan alat pada proses pengeringan yang dalam hal ini adalah mengetahui waktu minimum pada kadar kering yang maksimum digunakan analisis grafik. Data yang diperoleh dimasukkan table, kemudian hubungan keseluruhan data ditampilkan dalam bentuk grafik.Untuk memperoleh temperatur-temperatur yang diinginkan guna mengetahui keefektifan alat dalam hal kecukupan panas, dilakukan pengukuran temperature pada lingkungan, pada plat, dan pada ruangan oven.

\section{HASIL DAN PEMBAHASAN}

\section{A. Hasil}

Pada penelitian ini sampel uji yang digunakan adalah kayu basah dengan massa yang berbeda-beda. Sampel uji tersebut antara lain sampel uji A dengan massa 88 gram, sampel uji B dengan massa 93 gram, sampel uji C dengan 105 gram, sampel uji D dengan massa 110 gram, dan sampel uji E dengan massa 125 gram. Adapun hasil dari penelitian tersebut adalah sebagai berikut:

\section{a. Sampel Uji A dengan Massa 88 gram}

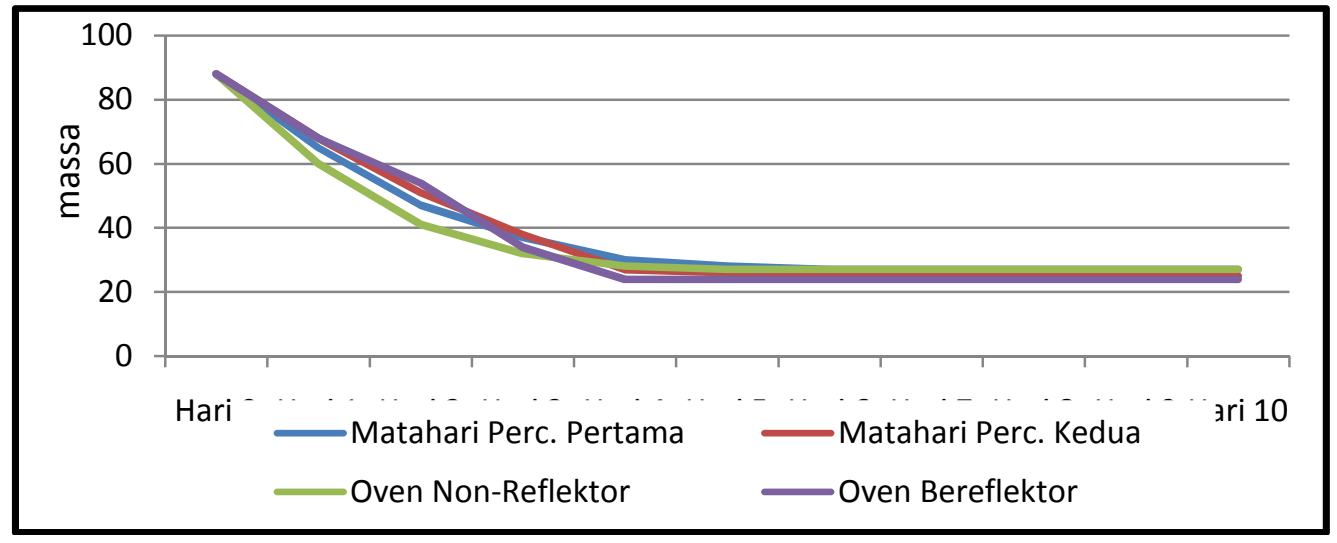

Grafik 1: Laju Pengurangan Massa pada Sampel Uji Bahan A

Table 2: Jumlah Waktu yang Dibutuhkan untuk Mencapai Nilai Kering Maksimum pada Masing-masing Jenis Pengeringan. Dan Nilai Penguapan (Kadar Air) dalam Persen Pada Sampel Uji A.

\begin{tabular}{|c|c|c|c|c|c|c|c|c|}
\hline \multirow{2}{*}{ sampel } & \multicolumn{2}{|c|}{ Matahari pertama } & \multicolumn{2}{|c|}{ Matahari kedua } & \multicolumn{2}{|c|}{$\begin{array}{c}\text { Oven non- } \\
\text { reflektor }\end{array}$} & \multicolumn{2}{|c|}{ Oven bereflektor } \\
\hline \multirow{2}{*}{ A } & $\begin{array}{c}\text { waktu } \\
\text { (hari) }\end{array}$ & $\begin{array}{c}\text { Kadar } \\
\text { air (\%) }\end{array}$ & $\begin{array}{c}\text { waktu } \\
\text { (hari) }\end{array}$ & $\begin{array}{c}\text { Kadar } \\
\text { air }(\%)\end{array}$ & $\begin{array}{c}\text { waktu } \\
\text { (hari) }\end{array}$ & $\begin{array}{c}\text { Kadar } \\
\text { air (\%) }\end{array}$ & $\begin{array}{c}\text { waktu } \\
\text { (hari) }\end{array}$ & $\begin{array}{c}\text { Kadar } \\
\text { air (\%) }\end{array}$ \\
\cline { 2 - 9 } & 6 hari & 69.32 & 6 hari & 71.59 & 5 hari & 69.32 & 4 hari & 72.73 \\
\hline
\end{tabular}




\section{a. Sampel Uji B Dengan Massa 93 gram}

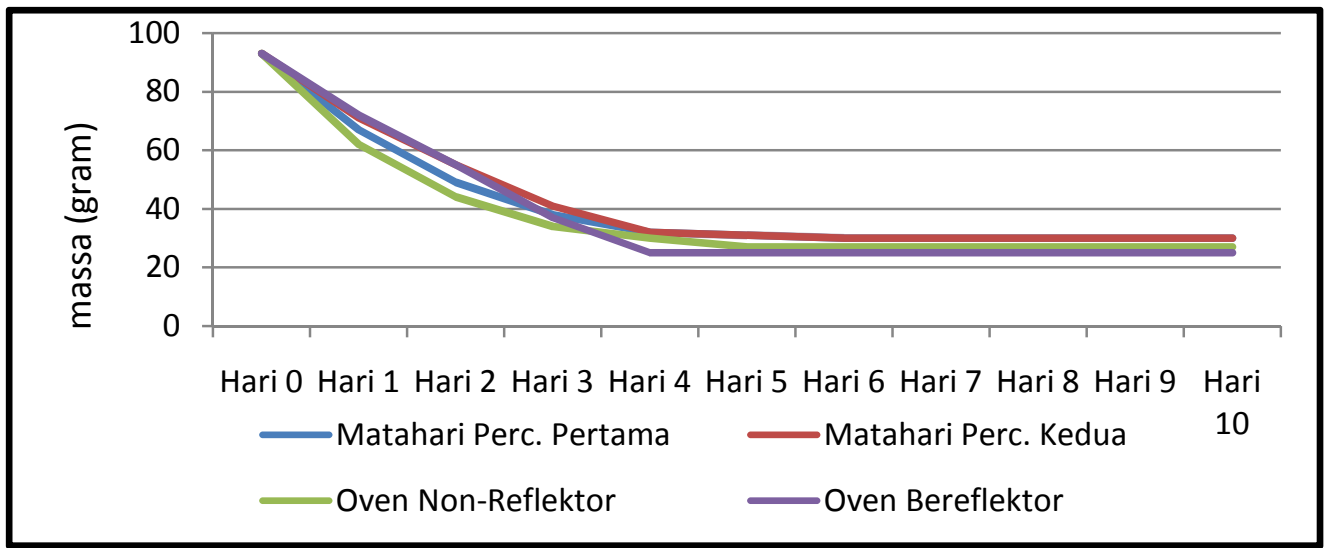

Grafik 2: Laju Pengurangan Massa pada Sampel Uji Bahan B

Table 3: Jumlah Waktu yang Dibutuhkan untuk Mencapai Nilai Kering Maksimum pada Masing-masing Jenis Pengeringan. Dan Nilai Penguapan (Kadar Air) pada Sampel Uji B

\begin{tabular}{|c|c|c|c|c|c|c|c|c|}
\hline \multirow{2}{*}{ sampel } & \multicolumn{2}{|c|}{ Matahari 1 } & \multicolumn{2}{c|}{ Matahari 2 } & \multicolumn{2}{c|}{$\begin{array}{c}\text { Oven non } \\
\text { reflektor }\end{array}$} & \multicolumn{2}{c|}{ Oven bereflektor } \\
\hline \multirow{2}{*}{ B } & $\begin{array}{c}\text { waktu } \\
\text { (hari) }\end{array}$ & $\begin{array}{c}\text { Kadar } \\
\text { air (\%) }\end{array}$ & $\begin{array}{c}\text { waktu } \\
\text { (hari) }\end{array}$ & $\begin{array}{c}\text { Kadar } \\
\text { air (\%) }\end{array}$ & $\begin{array}{c}\text { waktu } \\
\text { (hari) }\end{array}$ & $\begin{array}{c}\text { Kadar } \\
\text { air (\%) }\end{array}$ & $\begin{array}{c}\text { waktu } \\
\text { (hari) }\end{array}$ & $\begin{array}{c}\text { Kadar } \\
\text { air (\%) }\end{array}$ \\
\cline { 2 - 9 } & 6 & 67.74 & 6 & 67.74 & 5 & 70.97 & 4 & 73.12 \\
\hline
\end{tabular}

\section{a. Sampel Uji C dengan Massa 105 gram}

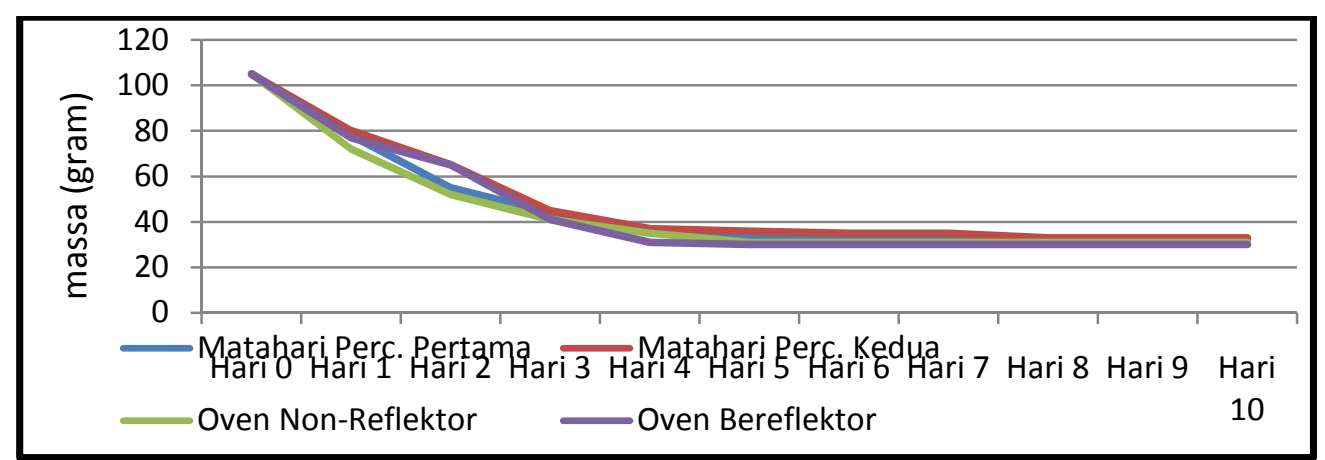

Grafik 3 Laju Pengurangan Massa pada Sampel Uji C

Table 4 Jumlah Waktu yang Dibutuhkan untuk Mencapai Nilai Kering Maksimum pada Masing-masing Jenis Pengeringan. Dan Nilai Penguapan (Kadar Air) dalam Persen Pada Sampel Uji C

\begin{tabular}{|c|c|c|c|c|c|c|c|c|}
\hline sampel & \multicolumn{2}{|c|}{ Matahari 1} & \multicolumn{2}{|c|}{ Matahari 2} & \multicolumn{2}{|c|}{$\begin{array}{l}\text { Oven non } \\
\text { reflektor }\end{array}$} & \multicolumn{2}{|c|}{ Oven bereflektor } \\
\hline $\mathrm{C}$ & $\begin{array}{l}\text { waktu } \\
\text { (hari) }\end{array}$ & $\begin{array}{l}\text { Kadar } \\
\text { air (\%) }\end{array}$ & $\begin{array}{l}\text { waktu } \\
\text { (hari) }\end{array}$ & $\begin{array}{l}\text { Kadar } \\
\text { air (\%) }\end{array}$ & $\begin{array}{l}\text { waktu } \\
\text { (hari) }\end{array}$ & $\begin{array}{l}\text { Kadar } \\
\text { air (\%) }\end{array}$ & $\begin{array}{l}\text { waktu } \\
\text { (hari) }\end{array}$ & $\begin{array}{l}\text { Kadar } \\
\text { air }(\%)\end{array}$ \\
\hline & 6 & 69.52 & 8 & 68.57 & 5 & 70.48 & 4 & 71.43 \\
\hline
\end{tabular}




\section{b. Sampel UjiD dengan Massa 110 gram}

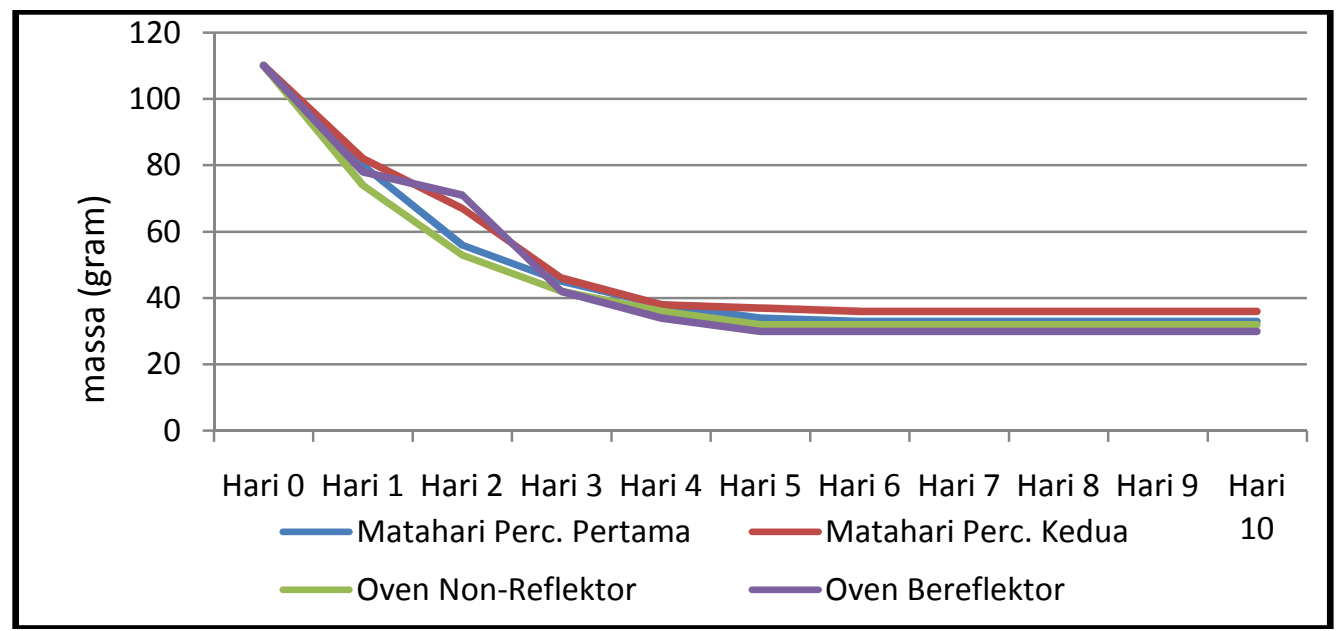

Grafik 4 Laju Pengurangan Massa pada Sampel Uji D

Table 5:Jumlah Waktu yang Dibutuhkan untuk Mencapai Nilai Kering Maksimum pada Masing-masing Jenis Pengeringan. Dan Nilai Penguapan (Kadar Air) dalam Persen Pada Sampel Uji D

\begin{tabular}{|c|c|c|c|c|c|c|c|c|}
\hline \multirow{2}{*}{ sampel } & \multicolumn{2}{|c|}{ Matahari 1 } & \multicolumn{2}{c|}{ Matahari 2 } & \multicolumn{2}{c|}{$\begin{array}{c}\text { Oven non } \\
\text { reflektor }\end{array}$} & \multicolumn{2}{c|}{ Oven bereflektor } \\
\hline \multirow{2}{*}{ D } & $\begin{array}{c}\text { waktu } \\
\text { (hari) }\end{array}$ & $\begin{array}{c}\text { Kadar } \\
\text { air (\%) }\end{array}$ & $\begin{array}{c}\text { waktu } \\
\text { (hari) }\end{array}$ & $\begin{array}{c}\text { Kadar } \\
\text { air (\%) }\end{array}$ & $\begin{array}{c}\text { waktu } \\
\text { (hari) }\end{array}$ & $\begin{array}{c}\text { Kadar } \\
\text { air (\%) }\end{array}$ & $\begin{array}{c}\text { waktu } \\
\text { (hari) }\end{array}$ & $\begin{array}{c}\text { Kadar } \\
\text { air (\%) }\end{array}$ \\
\cline { 2 - 9 } & 6 & 70.00 & 6 & 67.27 & 5 & 70.91 & 5 & 72.73 \\
\hline
\end{tabular}

\section{c. Sampel UjiE dengan Massa 125 gram}

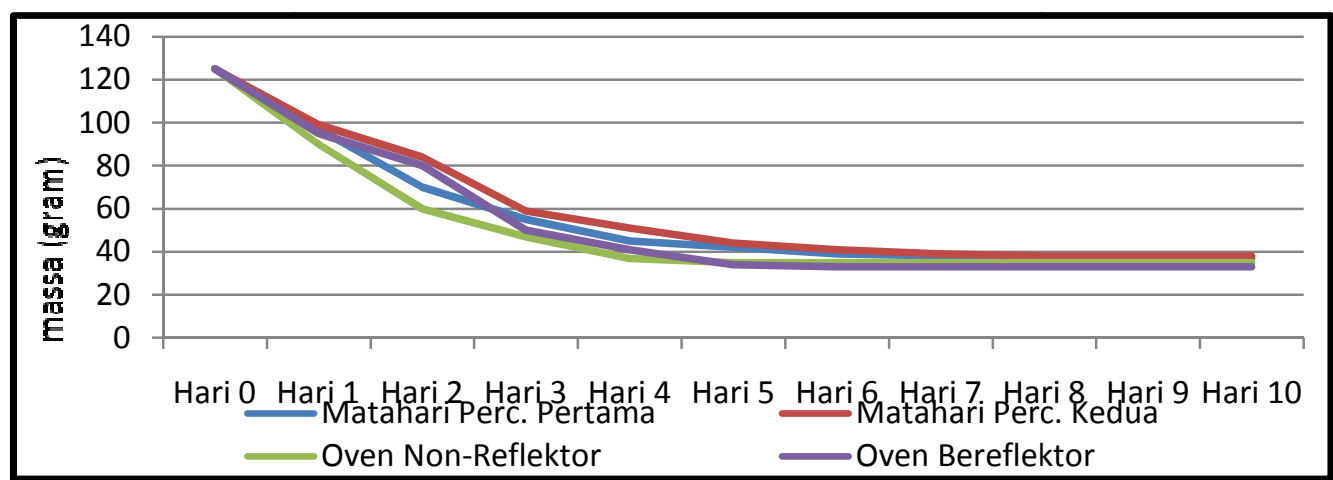

Grafik 5: Laju Pengurangan Massa pada Sampel Uji E

Table 6:Jumlah Waktu yang Dibutuhkan untuk Mencapai Nilai Kering Maksimum pada Masing-masing Jenis Pengeringan. Dan Nilai Penguapan (Kadar Air) dalam Persen Pada Sampel Uji E

\begin{tabular}{|c|c|c|c|c|c|c|c|c|}
\hline \multirow{2}{*}{ sampel } & \multicolumn{2}{|c|}{ Matahari 1 } & \multicolumn{2}{c|}{ Matahari 2 } & \multicolumn{2}{c|}{$\begin{array}{c}\text { Oven non } \\
\text { reflektor }\end{array}$} & \multicolumn{2}{c|}{ Oven bereflektor } \\
\hline \multirow{2}{*}{ E } & $\begin{array}{c}\text { waktu } \\
\text { (hari) }\end{array}$ & $\begin{array}{c}\text { Kadar } \\
\text { air (\%) }\end{array}$ & $\begin{array}{c}\text { waktu } \\
\text { (hari) }\end{array}$ & $\begin{array}{c}\text { Kadar } \\
\text { air (\%) }\end{array}$ & $\begin{array}{c}\text { waktu } \\
\text { (hari) }\end{array}$ & $\begin{array}{c}\text { Kadar } \\
\text { air (\%) }\end{array}$ & $\begin{array}{c}\text { waktu } \\
\text { (hari) }\end{array}$ & $\begin{array}{c}\text { Kadar } \\
\text { air (\%) }\end{array}$ \\
\cline { 2 - 9 } & 8 & 70.4 & 8 & 69.6 & 6 & 72 & 5 & 73.6 \\
\hline
\end{tabular}




\section{d. Temperatur Rata-rata pada Pengamatan Tanggal 10-20 Oktober 2011}

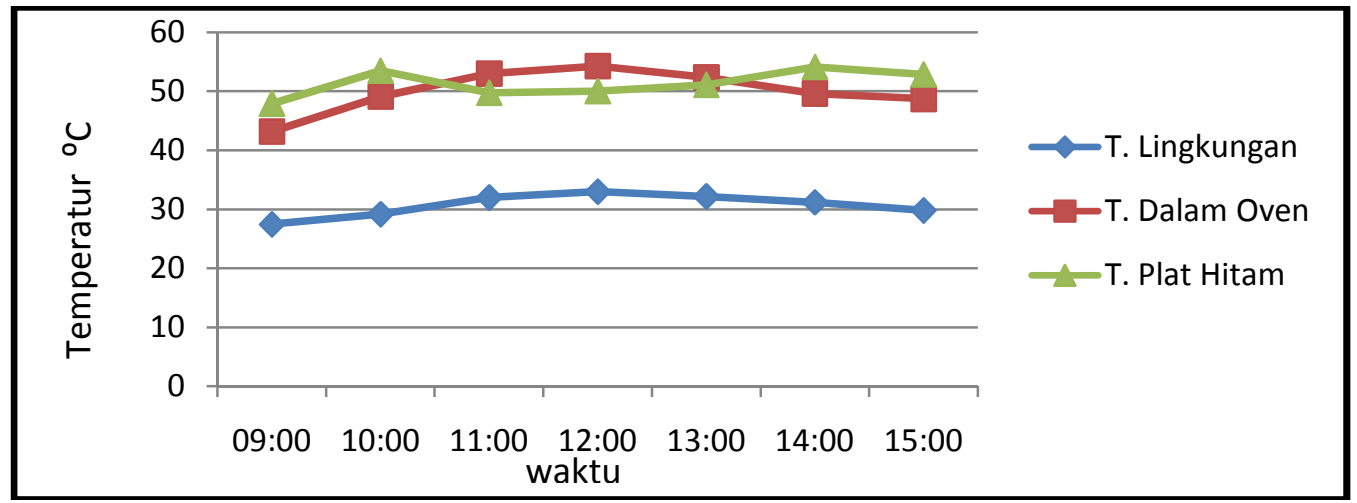

Grafik 6: karakteristik temperature rata-rata lingkungan, temperature rata-rata dalam oven, dan temperature rata-rata Plat Hitam pada percobaan tanggal 10-20 oktober 2011

\section{e. Temperatur Rata-rata yang Dapat Diukur pada Peengeringan Oven} Menggunakan Reflektor Terkontrol

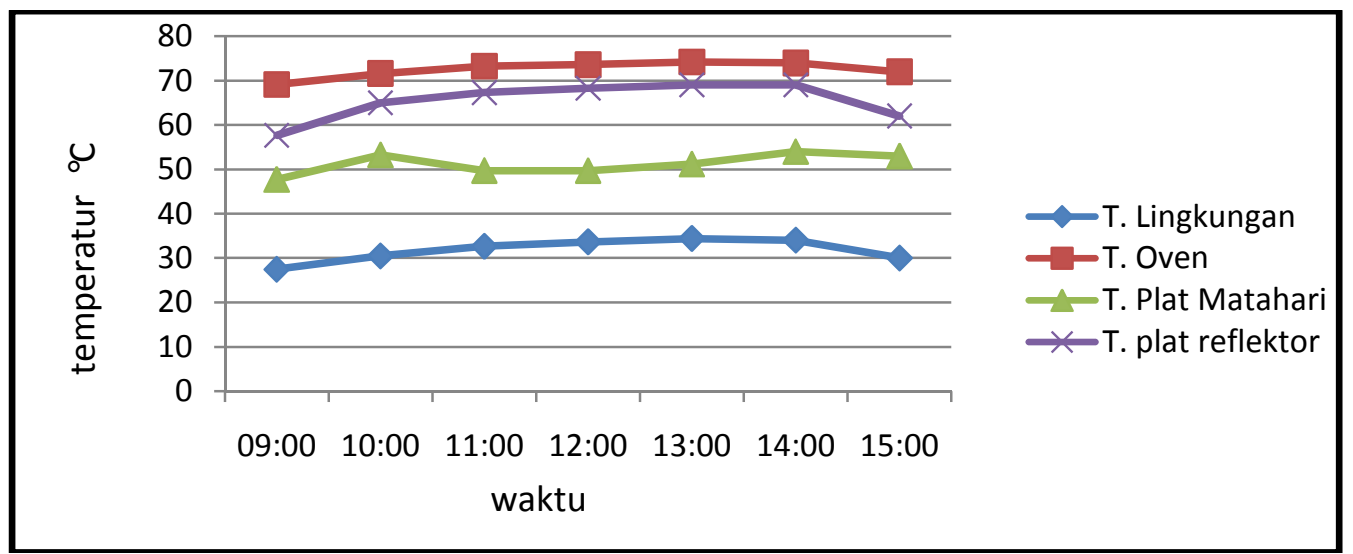

Grafik 7: Temperature Rata-Rata Lingkungan, Temperature Rata-Rata Dalam Oven, Dan Temperature Rata-Rata Plat Hitam Pada Percobaan dengan Menggunakan Oven Reflektor

\section{B. Pembahasan}

Desain alat dalam pembuatan sebuat alat mempunyai fungsi yang sangat penting, karena desain sangatmempengaruhi hasil yang akan dicapai. Pada skripsi ini penulis mendesain alat sedemikian rupa untukmemperoleh hasil yang maksimal. Selain itu, desain alat harus dibuat sesederhana mungkin sehingga masyarakat yang ingin membuat alat seperti yang penulis rancangini dapat mudah untuk mengerjakannya sendiri. Dengan demikian alat ini diharapkan dapat memenuhi kebutuhan masyarakat khususnya masyarakat dibidang permebelan.

Matahari menjadi petimbangan yang pertama dalam desain pembuatan alat ini karena indonesia merupakan daerah sekitar katulistiwa dan daerah tropis dengan luas daratan hampir 2 juta $\mathrm{km}^{2}$, dikaruniai penyinaran matahari lebih dari 6 jam sehari atau sekitas 2.400 jam dalam setahun dan mempunyai intensitas antara $0,6-0,7 \mathrm{~kW} / \mathrm{m}^{2}$. Bahan untuk kolektor terbuat dari aluminium dan seng. Untuk alumunium dipasang pada lapisan 
atas kedua setela kaca dengan model diberi lubang berdiameter $3 \mathrm{~cm}$ untuk mentransfer panas dari ruangan kaca ke ruangan jemur bahan, dan untuk seng dipergunakan sebagai dinding oven. Pemilihan bahan alumunium ini didasarkan pada beberapa pertimbangan diantaranya adalah: (1) nilai konduktivitasnya terbaik setelah tembaga,(2) tidak mudah mengalami korosi, (3) harganya relatif lebih murah dibandingkan tembaga. Untuk pemilihan bahan seng didasarkan pada pertimbangan: (1) merupakan bahan konduktor,(2) mudah diperoleh di lingkungan sekitar, (3) harganya sangat murah. (4) seng berpermukaan mengkilat sehingga di lapisan dalam tidak perlu dicat mengkilat guna memperkecil panas yang keluar oven. Untuk memaksimalkan panas yang diperoleh, maka kedua bahan tersebut dicat hitam agar dapat lebih banyak menyerap panas yang berasal dari radiasi sinar matahari.Bahan pada desain berikutnya adalah kaca transparan. Perletakan kaca sebagai atap pada desain ini karena Kaca hanya dapat melewatkan cahaya dengan panjang gelombang tertentu yang kecil sehingga ketika panjang gelombang cahaya membesar maka cahaya tidak akan dapat keluar dari rumah kaca lagi karena panjang gelombangnya membesar dan energinya akan membuat suhu dalam rumah kaca menjadi sangat panas karena terakumulasi terus menerus.Dipergunakan dua cermin reflektor yang masing-masing ditaruh di samping kanan dan kiri oven dengan arah menghadap dan berlawanan dengan datangnya sinar matahari. Reflektor tersebut berfungsi untuk memantulkan sinar matahari kepermukaan dinding oven yang tidak mendapat sinar matahari langsung.

Suatu alat pengeringan bisa dikatakan bagus dan maksimal kerjanya (pengeringan optimal) apabila dalam proses pengeringan, waktu yang dibutuhkan untuk kering bahan maksimum adalah cepat dan massa kering bahan maksimum pada nilai prosentasi penguapan kadar air adalah besar.

Pada pengujian alat dilakukan dengan membandingkan hasil keseluruhan nilai yang diperoleh pada pengukuran-pengukuran terkait. Dalam hal ini adalah kadar air, waktu kering massa maksimum dan temperatur.Untuk oven non-reflekor sendiri menghasilkan data pengukuran sebagai berikut: penguapan kadar air dan waktu kering maksimum pada sampel uji A adalah $69.32 \%$ dan 5 hari, penguapan kadar air dan waktu kering maksimum pada sampel uji B adalah $70.97 \%$ dan 5 hari, penguapan kadar air dan waktu kering maksimum pada sampel uji C adalah $70.48 \%$ dan 5 hari, penguapan kadar air dan waktu kering maksimum pada sampel uji D adalah $70.48 \%$ dan 5 hari,dan penguapan kadar air dan waktu kering maksimum pada sampel uji $\mathrm{E}$ adalah $70.91 \%$ dan 5 hari.

Hasil pada pengeringan dalan oven non-reflektor di atas tersebut lebih optimal dari pada pengeringan di bawah matahari. Adapun hasil pengukuran pada pengeringan di bawah matahari adalah sebagai berikut: penguapan kadar air dan waktu kering maksimum pada sampel uji A adalah $69.32 \%$ dan 6 hari. penguapan kadar air dan waktu kering maksimum pada sampel uji B adalah $67.74 \%$ dan 6 hari, penguapan kadar air dan waktu kering maksimum pada sampel uji C adalah 69.52\% dan 6 hari, penguapan kadar air dan waktu kering maksimum pada sampel uji D adalah $70 \%$ dan 6 hari,dan penguapan kadar air dan waktu kering maksimum pada sampel uji E adalah $70.40 \%$ dan 8 hari. 
Walaupun pada oven non-reflektor diperoleh hasil pengeringan yang optimal daripada pengeringan di bawah matahari. Pengeringan bisa lebih optimal dengan memberi reflektor pada oven guna meningkatkan panas yang sangat dibutuhkan dalam pengeringan. Dengan harapan hasil pengeringannya lebih optimal. Reflektor sesuai fungsinya adalah penarima sinar matahari untuk kemudian dipantulkan ke permukaan oven yang tidak mendapat ssinar matahari langsung. Dan pada oven dengan memanfaatkan reflektor diperoleh hasil sebagai berikut: penguapan kadar air dan waktu kering maksimum pada sampel uji A adalah $72.73 \%$ dan 4 hari, penguapan kadar air dan waktu kering maksimum pada sampel uji B adalah $73.12 \%$ dan 4 hari, penguapan kadar air dan waktu kering maksimum pada sampel uji C adalah $71.43 \%$ dan 4 hari, penguapan kadar air dan waktu kering maksimum pada sampel uji D adalah $72.73 \%$ dan 5 hari, dan penguapan kadar air dan waktu kering maksimum pada sampel uji E adalah $73.60 \%$ dan 5 hari.

Untuk hasil pengamatan temperature dapat dilihat pada grafik6 dan grafik 7Adapun karakteristik temperature rata-rata dalam oven dari pengukuran antara oven yang menggunakan reflector dengan oven yang tidak menggunakan reflector dapat dilihat pada grafik dibawah ini:

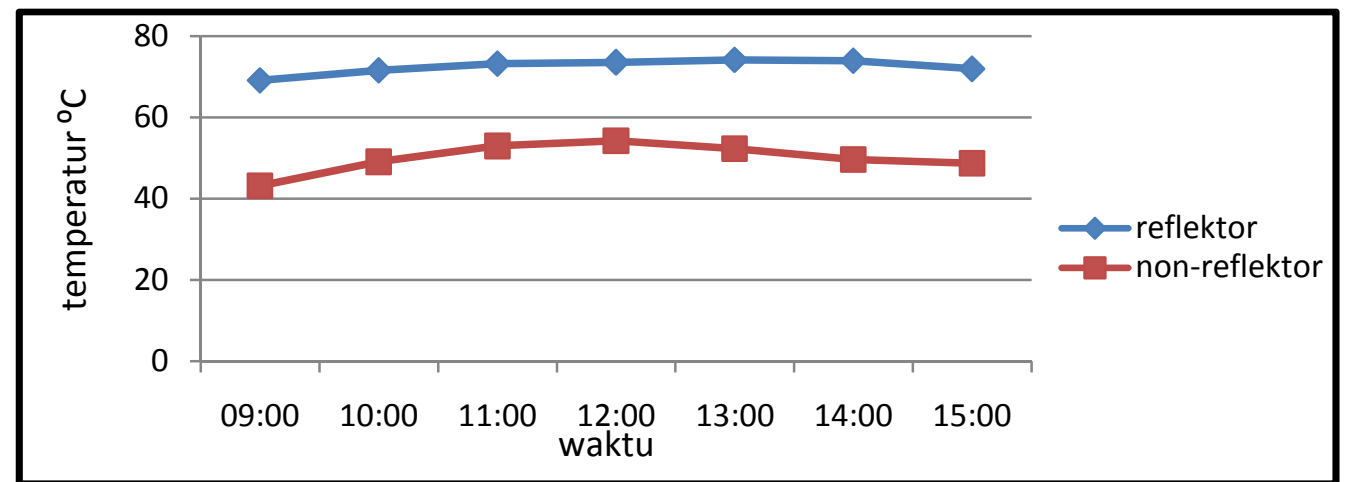

Grafik 8: Karakteristik Temperature pada Oven Menggunakan Reflector Dan Oven Tidak Menggunakan Reflector

Alat ini dikatakan efisian,portable dan praktis karena alat ini dapat mengeringkan kayu dengan cepat, dengan hasil pengeringan yang maksimal, dan tidak membutuhkan biaya yang mahal serta mudah untuk membuatnya bagi semua kalangan masyarakat yang hendak membuat dengan desain yang penulis tawarkan. Alat ini bisa dipergunakan dalam jangka waktu yang lama atau mobile, karena alat ini menggunaka radiasi dari sinar matahari sebagai sumber energi utamanya.

\section{KESIMPULAN}

1. Pada desain alat ini matahari menjadi petimbangan yang pertama sebagai sumber energi. Perintah untuk memanfaatkan matahari diterangkan dalam Al-Qur'an pada Surat al-Isra' ayat 12. Menggunakan kolektor plat hitam. Perletakan kaca sebagai atap karena Kaca akan membuat suhu dalam ruangannya menjadi sangat panas. dua cermin reflektor untuk memantulkan sinar matahari ke semua dinding oven. 
2. Pengeringan menggunakan oven reflektor terkontrol adalah pengeringan yang paling optimal dibandingkan dengan oven tanpa reflektor dan juga pengeringan matahari. Untuk tingkat panas pada oven, pada Temperatur oven yang menggunakan reflektor panasnya lebih tinggi dari pada yang tidak menggunakan reflektor.

3. Alat ini dapat dikatakan efisian, portable dan praktis karena alat ini mampu mengeringkan kayu dengan cepat, dengan hasil pengeringan yang maksimal, sederhana dan mudah dibuat, dan tidak membutuhkan biaya yang mahal. Alat ini bisa dipergunakan secara mobile, karena alat ini menggunaka radiasi dari sinar matahari sebagai sumber energi utamanya.

\section{DAFTAR PUSTAKA}

Amoranto, Trisnobudi. 2003. Catatan Kuliah Fenomena Gelombang. Bandung: ITB

Anonymus. 2009.Masalah Energi dan Upaya Pemanfaatan Energi Surya Cara Langsung Sebagai Salah Satu Sumber Energi Alternatif, Proceding Seminar Sel Fotovoltaik Indonesia, Bandung: LAPI_ITB

Aris, W. 1995. Teknologi Rekayasa Surya. Bandung : Pradnya Paramita

Coffey, J. 2010.Does The Sun Rotate.Universe Today

Felix Yap, K.H. 1964. Konstruksi Kayu. Bandung: Binacipta

Giancoli, C. Dauglas. 2001. Fisika Jilid 1. Jakarta: Erlangga

Graham, Ian. 2005. Intisari Ilmu Ruang Angkasa penerjemah Hindrina Perdhanasari. Jakarta: Erlangga

Gunawan, DT. 2004. Konstruksi Kayu.Bandung: Universitas Parahyanga

Hermawan, WM. 2004. Termodinamika dan perpindahan kalor. Bandung: Rosda

Holman,J.P. 1994. Perpindahan Kalor. Jakarta: Erlangga

Koestoer, Raldi Artono.2002. Perpindahan Kalor. Jakarta: Salemba teknik

Lang, KR. 2003. The Cambridge Guid to The Solar System. Cambridge: Cambridge University Press

Lang, Kenneth R. 2006. Departemant of Physin and Astronomi.robinson hall, usa: Tufts University Medford

Manan, Saiful. 2009. Energi Matahari, Sumber Energi Alternatif yang Effisien, Handal dan Ramah Lingkungan di Indonesia. Semarrang: Fakultas Teknik Universitas Diponegoro

Rosidah, Lailatul. 2009.Oven pengering kayu terbaru: malangraya.web.id

Sitompul, Darwin dan Kusnul hadi.1984. Prinsip-prinsip Konversi Energi. Jakarta: Erlangga 
Soeyanto, BM. 1974. Pengantar Perkayuan. Yokyakarta: kanisius

Tjasyono, Bayong. 2003, Geosains, Bandung: ITB

Tjasyono, Bayong.2006. Ilmu Kebumian dan Antariksa. Bandung: Rosdakarya

UI. 2008. Bahan Konstruksi. Jakarta: Fakultas Teknik Sipil dan Perencanaan

Sears dan Zemansky. 2003. Fisika Universitas. Bandung: Binacipta 